\title{
artigo
}

\section{Consumo de marcas de moda: aspectos funcionais e simbólicos}

\author{
Consumption of fashion \\ brands: functional \\ and symbolic aspects
}

\section{[ ANA PAULA DE MIRANDA ]}

Ana Paula de Miranda é doutora em Marketing pela FEA-USP. Professora de Teoria do Consumo do Mestrado Profissional em Gestão Empresarial da Faculdade Boa Viagem (FBV-PE). É diretora de negócios da Modus Marketing \& Semiótica.

E-mail: anapaula.miranda@modusmkt.com

[resumo] Esta pesquisa tem o objetivo de apresentar os aspectos procurados pelas consumidoras de marcas de moda. Os resultados encontrados em ordem de importância foram: Busca de resultado - marcas funcionais; Busca pela sedução - marcas "peruas"; Busca pelo look - marcas "estilosas"; Busca pela liberdade - marcas independentes; Busca pela autoria - marcas individualizadoras; Busca pela novidade - marcas modernas; Busca pela individualidade - marcas "metidas"; Busca pela segurança - marcas maternais; Busca pelo prestígio - marcas suntuárias. 0 de maior grau de significância é o funcional, ou seja, cumprir com os aspectos funcionais é condição básica para o consumo; os aspectos simbólicos passam a ser os diferenciadores.

\section{[palavras-chave]}

moda; consumo; marcas.

[abstract] This research has the objective to present the aspects looked for the consumers of fashion brands. The following results were identified: Search of result - functional brands; Search for the seduction - brands show off; Search for look - hype brands; Search for the freedom - independent brands; Search for the authorship - individual brands; Search for the newness - modern brands; Search for the individuality - arrogant brands; Search for the security - maternal brands; Search for prestige - compiscous brand. Functional aspects is basic condition for the consumption, separate resulted the symbolic aspects starts to be differentiations. 
Produtos, comportamentos de consumo, compras, mercados, escolhas, decisões podem ser encarados como trocas simbólicas que se fazem na sociedade contemporânea. 0 consumo, sob essa perspectiva, é processo de comunicação e classificação de pessoas e objetos (Rocha, 1995). Portanto, o consumo pode ser visto como dimensão simbólica da cultura.

0 objetivo deste trabalho foi considerar a relação entre identidade social e interação social mediante a escolha das mensagens de comunicação embutidas na decisão de compra relativa a marcas de moda.

0 reconhecimento do valor simbólico de bens e serviços é o caminho para a criação de atitudes positivas em relação a produtos, a marcas e lojas que expressam os valores individuais das pessoas. Todo o objeto comercial tem caráter simbólico: 0 ato de comprar envolve a avaliação do seu simbolismo, para decidir se é ou não adequado ao seu comprador.

As empresas em geral devem vigiar para que as suas expectativas de sucesso, ligadas ao objetivo de obtenção de lucro, se consolidem; elas dependem, fundamentalmente, de uma atuação mercadológica voltada para a compreensão do valor simbólico associado a produtos e marcas, e como esta dimensão pode auxiliar o indivíduo no desempenho dos diferentes papéis assumidos na vida cotidiana e perante a sociedade.

\section{Significado das marcas}

Desmond (2003) chama a atenção para que o produto inicialmente não possui significado próprio. Um perfume é um perfume, tem função de perfumar, passa a assumir uma personalidade quando é atribuído de marca que o distingue como a marca Chanel que não só herdou o nome, mas os significados de sua fundadora ${ }^{[1]}$, bem como usou imagens do sistema de celebridades como Catherine Deneuve, Marylin Monroe e Nicole Kidman, de onde extrai da imagem destes "modelos" os significados para seu perfume e demais produtos. Esta atribuição de significados serve, principalmente, para diferenciar a mesma categoria de produto para marcas diferentes.

0 indivíduo, ao manifestar o seu eu no ato de consumo, imita, representa e cria mecanismos simbólicos para instaurar a comunicação, abrindo, assim, o diálogo com o mundo. Desempenha o papel de ator, de observador e observado, estabelecendo relação com o meio em que vive atuando no tempo e espaço. A imagem, como uma cena silenciosa ou como textos aparentemente sem vida, mas intensos, embora apresentados como composições fisicamente estáticas, é capaz de contar, comunicar, transmitir uma idéia, um sentimento, utilizando essencialmente elementos visuais entrelaçados e estruturados, que necessariamente afetam quem observa.

No perfume Chanel, o significado atribuído à marca é sofisticação e, para Givenchy, é feminilidade; antes de Nicole Kidman, outro nome associado a Chanel nas campanhas publicitárias foi Catherine Deneuve, e para Givenchy quem melhor personificou o valor simbólico da marca foi Audrey Hepburn. De forma que, quando alguém consome 0 perfume Chanel, passa a ser, ou se sente como, ou ainda é, percebido pelos outros como sofisticada; já no caso de Givenchy, a percepção é de ser extremamente feminina. Assim o produto passa a ser um gerador de significados (Desmond, 2003). Lembrando que estes símbolos e signos tanto podem dizer a verdade quanto podem mentir.

Segundo Sartre (1997), o desejo é

\section{Quadro 1 - Sistema de referência}

\begin{tabular}{cccc}
\hline Nicole Kidman & $\neq$ & Liv Tyler & Sistema de Modelos \\
\hline " & & " & \\
\hline Chanel & $\neq$ & Givenchy & Sistema de Produtos \\
\hline
\end{tabular}


falta de ser e é diretamente sustentado no ser do qual é falta; sendo assim, o homem é o que não é e não é o que é. Sendo a realidade humana o empenho em ser, 0 desejo exprime este empenho. 0 desejo leva à busca do objeto. Mediante a sua posse, ou seja, desejar se arrumar, ter um objeto de adorno, fazer compras, significa desejar ter uma determinada aparência, definindo assim a relação: fazer, ter, ser.

0 conceito de marca resume bem as possibilidades da "linguagem do consumo". Quase todos os produtos se propõem hoje sob uma sigla imposta: cada produto tem marca que pode chegar até a substituir o nome, como Levi's foi durante certo tempo sinônimo de calça jeans. Em princípio, a função da marca é indicar o produto; mas em segundo, e não menos importante, é mobilizar as conotações afetivas.

A razão é de ordem econômica: sendo calculadora, a sociedade industrial está condenada a formar consumidores que não calculam. Para que haja o consumo antes do desgaste, faz-se necessário um imaginário constituído para despertar o desejo: não é o objeto, é o nome que o faz desejar; não é o sonho, é o símbolo que faz vender (Barthes, 1979).

Elliot (2004) apresenta a perspectiva do consumo como vocabulário simbólico, no qual o consumo é elemento da prática da identidade, por ser fonte de ação social e interpretações compartilhadas.

A teoria da autocongruência de Sirgy (1982) contribui afirmando que consumidores preferem produtos e marcas com significado, consistentes com seus autoconceitos; assim sendo, motivados por autoconsistência consumidores comparam seus autoconceitos com a imagem dos produtos e preferem produtos cujas imagens são congruentes com suas auto-imagens.

Existe uma interação entre a percepção dos consumidores sobre eles mesmos e sobre o uso que eles fazem dos produtos de moda e suas marcas como símbolos, existe uma relação entre esses produtos e suas marcas com o eu (Banister e Hogg, 2001).

Aaker (1999) encontrou evidências do efeito da congruência de personalidade. Pessoas preferem marcas com as quais elas compartilham caracteristicas de personalidade. Govers e Schoormans (2005) apresentam resultados de significante congruência positiva na relação produto-personalidade na preferência do consumidor para produtos de apelo privado como chaves de fenda, máquinas de café, porta-sabão líquido e vinhos de mesa.

0 desafio está em desvendar este sentido que objetiva maximizar a eficácia da comunicação; o símbolo é constituído de significante e de significado que lhe corresponde (Lévi-Strauss, 1989; Barthes, 1979); um significante pode possuir vários significados, diversos entre si, para várias pessoas, ou um significado pode ser atribuído a vários significantes diversos entre si; a linguagem do consumo só vai alcançar o seu objetivo se a comunicação for efetiva, se os códigos forem compartilhados. Estes são convencionados e compartilhados; assim os significados atribuídos aos produtos são transferidos com grande facilidade (Engel et al., 1991).

As marcas contam histórias. Consumidores interpretam imagens associadas com produtos ou marcas, altamente influenciadas por estereótipos generalizados do tipo de usuário deste produto (Banister e Hogg, 2001).

0 Brand Concept Management (BMC) propõe que a imagem de marca deve ser baseada em um conceito de marca ou um significado abstrato específico da marca (Park et al.,1986). De forma geral, o conceito de marca deve ser tanto simbólico como funcional. Marcas funcionais satisfazem aspectos práticos de necessidades imediatas. Marcas simbólicas satisfazem necessidades simbó- 
licas como auto-expressão e prestígio. Por exemplo, um relógio Casio atende à necessidade funcional de informar 0 horário exato; já um Movado pode ser considerado uma marca simbólica, pois é usado principalmente por seu apelo de status, fornecer a informação em relação ao passar das horas é um mero detalhe.

Ou seja, marcas apresentam aspectos simbólicos e funcionais. Segundo Bhat e Reddy (1998), faz-se necessária uma investigação empírica para identificar se simbolismo e funcionalismo são dois conceitos distintos ou são dois fins de um conceito de marca in continuum. Em seus estudos, eles apresentam três fatores que explicam este tipo de consumo, sendo um funcional e dois simbólicos (prestígio e expressão pessoal). Sendo assim, há dois conceitos distintos e não dois fins em comum para um conceito de marca.

As competências simbólicas são freqüentemente referenciadas na literatura como características representacionais. Os adjetivos e as frases que pertencem às competências simbólicas incluem o representacional, a expressão emocional do eu, a imagem do eu, a personalidade, o valor e o ícone. Marcas funcionam como uma sugestão para refletir a associação de consumidores com determinados grupos. Sendo assim, as características emocionais do simbólico (reflexo da auto-expressão) e os fatores representacionais (associação com grupos sociais) são incorporados à marca simbólica (Bridson e Evans, 2004).

A literatura sobre simbolismo de produtos e marcas mostra que roupas é uma categoria de consumo de alto envolvimento simbólico, pois pessoas avaliam as outras pelo que está visível, ou seja, suas roupas. A natureza simbólica do vestuário pode ser incorporada também por estilos, marcas, marcas de varejo, uniformes, hábitos de membros de uma subcultura em particular (Banister e Hogg, 2001) ${ }^{[2]}$.

Produtos de vestuário são ótimos veículos de comunicação para os seus proprietários. As marcas de moda possuem as características essenciais para o consumo simbólico: visibilidade, variabilidade no uso e personalização. Para que produtos tenham associações com a personalidade, têm de ser consumidos de forma que estejam visíveis; a variabilidade no uso é também importante, porque, sem esta, não existe diferenciação entre os indivíduos, com base no uso do produto; a personalização do produto denota a extensão mediante a qual o uso do produto pode se atribuido para uma imagem estereotipada de um uso generalizado (Sirgy, 1982). Por exemplo, ao escolher uma roupa pode-se escolher entre vários estilos (variabilidade), que podem comunicar diferentes mensagens que serão entendidas como expressões do eu (personalização) por todos os que a virem (visibilidade); já que a roupa é destinada ao ambiente público, a falta pode ser punida com a sua prisão; não ao privado, porque aí se pode ficar sem ela, se assim o desejar.

A dinâmica está em se identificar, a lógica deste processo se constitui na personalização e integração que caminham em paralelo: é o "milagre do sistema", do qual fala Baudrillard (1995); esta integração é o processo pelo qual o indivíduo se ajusta à sociedade e se socializa (Augras, 1967; Solomon, 1983; Engel et al., 1995).

\section{Metodologia}

A pesquisa utilizou o Critério de Classificação Econômica Brasil, realizado por um grupo de trabalho da ANEP (Associação Nacional de Empresas de Pesquisa ${ }^{[3]}$ com acompanhamento da ABA (Associação Brasileira de Anunciantes) e concordância da ABIPEME (Associação Brasileira 
de Institutos de Pesquisa de Mercado).

A população era feminina e pertencente às classes sociais $A, B$ e $C$, com idade entre 16 e 55 anos e residente em São Paulo. De acordo com o trabalho de Solomon e Schopler (1982), as muIheres são mais envolvidas com vestuário do que a população masculina; a relação entre autopercepção pública e a dimensão relativa ao vestuário são muito fortes para o sexo feminino o que justifica a escolha do universo feminino. McCracken e Roth (1989) encontraram em suas pesquisas que as mulheres são significativamente melhores habilitadas que os homens para interpretar a sintaxe do código do vestuário. Podemos afirmar que a moda tem historicamente criado uma associação forte entre feminilidade e a busca do "estar na moda", na qual se realça a importância da aparência na construção social da feminilidade. Logo, mulheres são mais suscetiveis às mensagens de moda que os homens (Thompson e Haytko, 1997).

Em relação à distribuição da amos- tra entre as classes sociais e os grupos de idade, foram definidas quotas de 27 questionários aplicados por segmento de classe social e de grupo de idade conforme o que está apresentado, totalizando 324 questionários. 0 questionário foi construído após fase qualitativa quando foi analisado o discurso de 24 consumidoras sobre os motivos que as levavam a consumir (ou não) marcas de moda.

\section{Análise dos resultados}

Para o desenvolvimento da tipologia das marcas baseada nos resultados da aplicação das escalas referentes aos aspectos sociais, motivacionais e comunicacionais do consumo de marcas de moda, foi utilizada a análise de cluster. Na análise do dendograma ${ }^{[4]}$, optou-se por fazer o corte em nove grupos por ser o nível intermediário e, portanto, o mais representativo, nem tão abrangente, nem tão segmentado. Foram identificados nove tipos de marcas, das quais oito apresentam características simbólicas e uma, o cluster

\section{Figura 1 - Apresentação dos clusters}

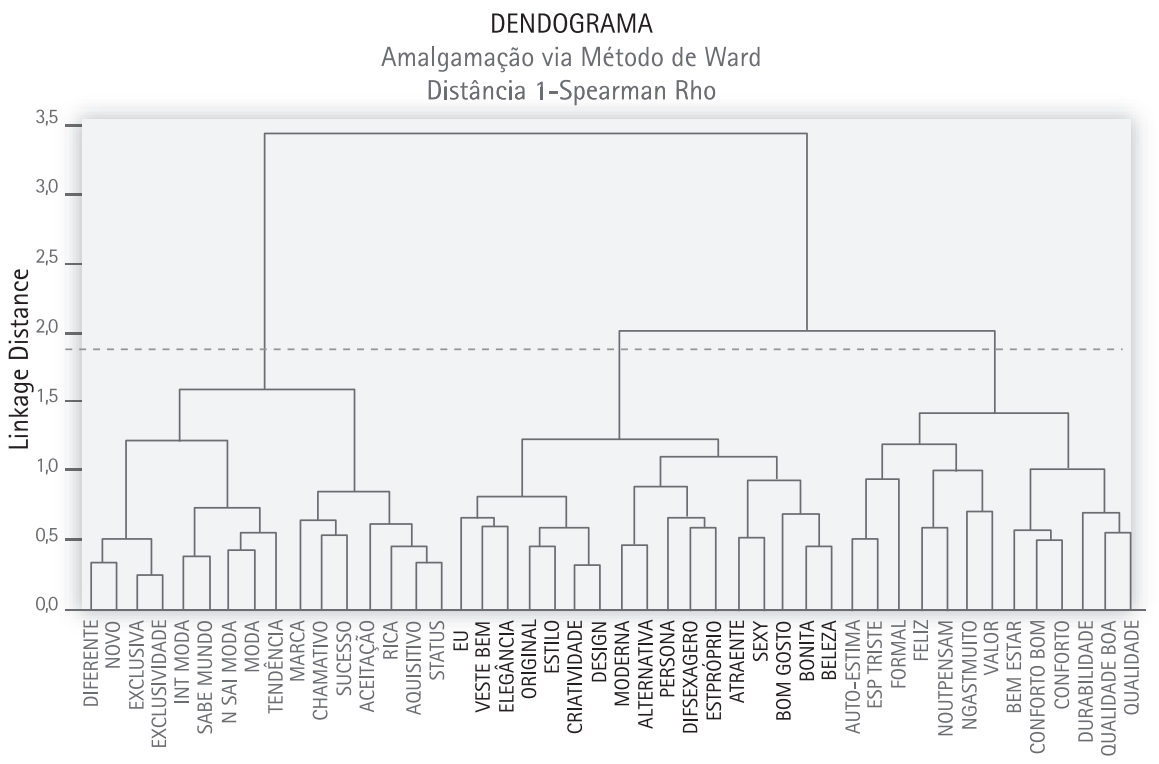




\section{Descrição dos clusters}

Cluster $1=$

(o diferente + o novo + que seja exclusiva + exclusividade) $/ 4=$

grupo das marcas dos que querem se destacar na multidão.

Busca pela individualidade mediante o consumo de marcas de moda.

\section{Cluster 2 =}

(interessada em moda + sabe o que esta acontecendo no mundo + não sair da moda + estar na moda + tendência) $/ 5=$

grupo das marcas dos modernos. Busca pela novidade mediante o consumo de marcas de moda.

\section{Cluster $3=$}

(identidade da marca + chamativo + sucesso + aceitação + rica + poder aquisitivo + status) $/ 7=$

grupo das marcas suntuárias. Busca pelo prestígio mediante o uso de marcas de moda.

\section{Cluster $4=$}

(eu + veste bem + elegância + original + estilo + criatividade + design)/7 = grupo das marcas "estilosas". Busca pelo look mediante o consumo de marcas de moda.

\section{Cluster $5=$}

(moderna + alternativa + mostrar que tem personalidade + diferente sem exagero + estilo próprio) $/ 5=$

grupo das marcas individualizadoras. Busca pela autoria mediante o uso de marcas de moda.

\section{Cluster $6=$}

(atraente + sexy + bom gosto + bonita + beleza) $/ 5=$ grupo das marcas "peruas". Busca da sedução mediante o uso de marcas de moda.

\section{Cluster $7=$}

(auto-estima + espantar tristeza + formal) $/ 3=$ grupo das marcas maternais. Busca de segurança mediante 0 uso de marcas de moda.

\section{Cluster $8=$}

(feliz + não importa o que os outros pensam + não gastar muito + valor) $/ 4=$ grupo das marcas independentes. Busca de liberdade mediante o uso de marcas de moda.

\section{Cluster $9=$}

(bem-estar + conforto + durabilidade + qualidade + qualidade) $/ 5=$ grupo das marcas funcionais. Busca de resultado mediante o uso de marcas de moda. 
Figura 2 - A importância dos clusters

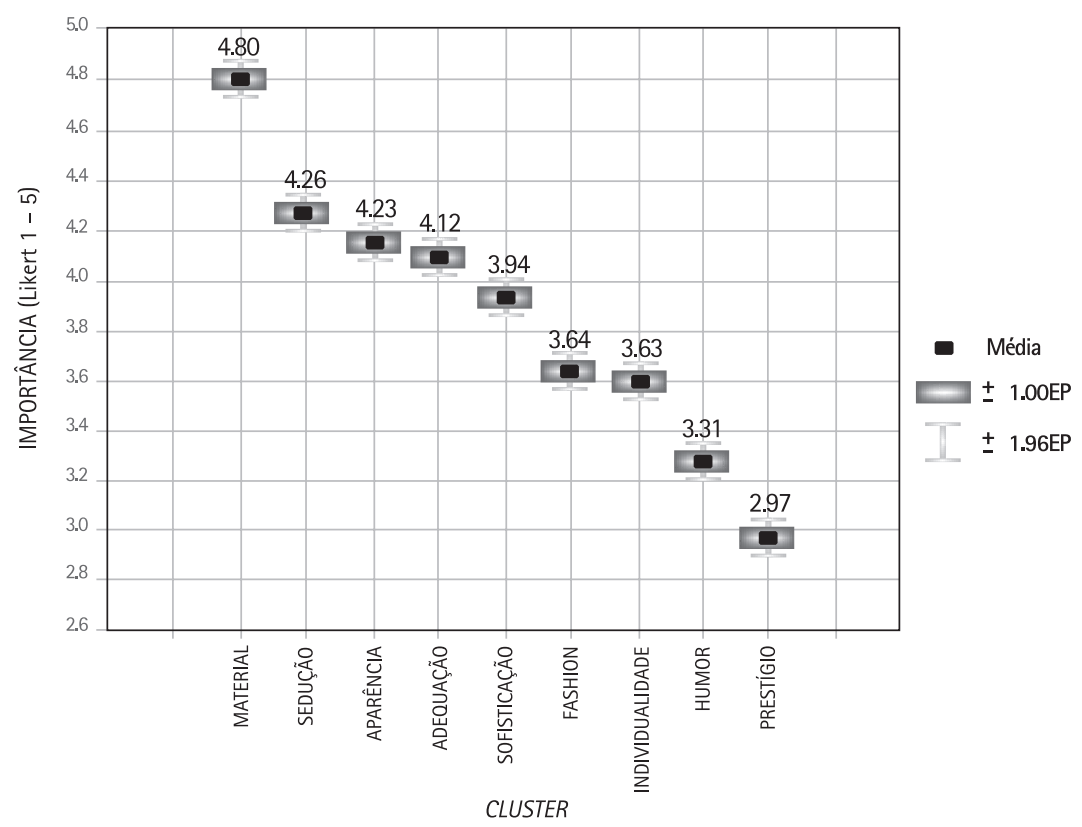

09, apresenta aspectos funcionais.

0 cluster 09, o das marcas funcionais, apresenta maior grau de significância, o que nos leva a afirmar que as questões relativas ao produto em si como qualidade do material, durabilidade, acabamento, modelagem são vitais para o sucesso de uma marca de moda; sem estas atribuições, a marca não tem competitividade no mercado. Trabalhar a imagem esquecendo os aspectos técnicos do produto é inaceitável por parte do consumidor.

Sedução (cluster 06) e o look (cluster 04) vêm em seguida, demonstrando que os aspectos mais "femininos" do consumo, os relativos a seduzir, a ter um estilo, ou seja, tudo o que leva à admiração do outro e que pode obter elogios que podem ser em forma de olhares ou palavras, são extremamente importantes para o consumo de marca de moda, sem esquecer que o look é processo de construção de identidade. Por outro lado, a liberdade (cluster 08) mostra a preocupação em afirmar quem tem liberdade de escolher de forma inteligente, não está disposta a pagar por este reconhecimento e que apresenta um nivel de significância tão alto quanto os outros dois, ou seja, existem tanto mulheres que vivem em função do outro como as que não estão preocupadas com isso.

Seguindo a ordem temos o cluster 05, o da autoria, que apresenta uma muIher que quer consumir marcas que não estejam sintonizadas com a massificação, que tenham uma assinatura, com a qual elas possam se identificar se projetar, como uma alternativa ao que foi definido como bonito ou de bom gosto pelo gosto comum.

Novidade e individualidade estão bem próximas, mostrando que a preocupação de estar na moda, de ser moderna, de ter a informação da tendência, a verdadeira espinha dorsal do que se acostumou chamar de fashion perde, numa visão geral, para aspectos de individualização e de bom senso que a marca pode atribuir ao seu proprietário, como é o caso dos clusters anteriores, mas ainda apresenta um alto nível de relevância para a consumidora.

A busca pela segurança das marcas maternais está presente mostrando que as mulheres ainda fazem terapia fashion com mais freqüência do que seria o recomendável, a fuga dos problemas e 0 uso do consumo de marcas como amuletos de transformação em pessoas mais corajosas, interessantes ou qualquer outro atributo que gere a aceitação e a admiração do grupo e, logo, a sua própria, é relevante para este consumo.

Por último, e apresentando baixa, relevância para as consumidoras em geral, estão as marcas suntuárias, ou seja, a busca pelo prestígio, ser reconhecida como uma pessoa que tem dinheiro não é interessante para as mulheres em geral, parece que não está na moda aparentar, é cafona ser perua. 


\section{Considerações finais}

Interessante o resultado de que, por mais que todos os outros clusters sejam de atribuição simbólica, o de maior grau de significância é o funcio- nal, ou seja, cumprir com os aspectos funcionais é condição sine qua non, os aspectos simbólicos passam a ser os diferenciadores.

Assim, podemos afirmar que, só quando as questões utilitárias estão resolvidas, a consumidora transcende para as questões simbólicas.

\section{REFERÊNCIAS}

AAKER, J. L The malleable self: the role of self-expression in persuasion. Journal of Marketing Research, v. 36, n², p. 45-57,1999.

AMARAL, M. A. Mademoiselle Chanel. 1 ed. São Paulo: Globo, 2004.

AUGRAS, M. A dimensão simbólica. Rio de Janeiro: Fundação Getúlio Vargas, 1967.

BANISTER, E.; HOGG, M. K.; Consumers and their negative selves, and the implications for fashion marketing. In: HINES, T.; BRUCE, M. Fashion Marketing: Contemporary lssues. 1. ed. Oxford: Ed. Butterworth-Heinemann, 2001.

BARTHES, R. Sistema da moda. São Paulo: Ed. NacionalEd. Nacional/Ed. da Universidade de São Paulo, 1979.

BAUDRILLARD, J. A sociedade de consumo. Rio de Janeiro/Lisboa: Elfos/Ed. 70, 1995.

BHAT, S; REDDY, S.K. Symbolic and functional positioning of brands. Journal of consumermarketing. v. 15. $n^{\circ} 1$, p. 32-43, 1998.

BRIDSON, K.; EVANS. J. The secret to a fashion advantage is brand orientation. International Journal of Retail\& Distribution Management, v. 32, n 8, p. 403-411, 2004.

DESMOND J. Consuming behaviour. 1 ed. Nova York: Palgrave Macmillan, 2003.

ELLIOT, R. "Making Up People: Consumption as a symbolic vocabulary for the construction of identity". In: EKSTROM, K.M.; BREMBECK H. (eds). Elusive Consumption. Oxford: BERG, 2004.

ENGEL, J. F.; WARSHAW, M. R.; KINNEAR, T. C. Promotional strategy:managing the marketing communications process. Estados Unidos: Irwin, 1991.

. BLACKWELL, R. D.; MINIARD, P. W. Consumer behavior. Estados Unidos: The Dryden Press, 1995.

GOVERS, P.C.M.; SCHOORMANS, J. P. L Product personality and its influence on consumer preference. Journal of Consumer Marketing, v. 22, nº 4, p. 189-197, 2005.

LÉVI-STRAUSS, C. O pensamento selvagem. Campinas/SP: Papirus, 1989.

McCRACKEN, G.; ROTH, V. Does clothing have a code? Empirical findings and theoretical implications in the study of clothing as a means of communication. International Journal of Research in Marketing. v. 6, p. 13-33, 1989.

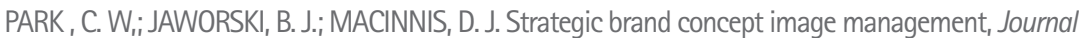
of Marketing, v. 50, Outubro, p. 135-45, 1986.

ROCHA, E. Totemismo e mercado: notas para uma antropologia do consumo. Revista Brasileira de Administração Contemporânea. Anais do 19 ENANPAD. v. I, n. 5, Marketing, 9/1995.

SARTRE. J. O ser e o nada - Ensaio de ontologia fenomenológica. Petrópolis: Vozes, 1997.

SIRGY, M. Joseph. Self-concept in consumer behavior: a crítical review. Journal of consumer research. v. 9, Dezembro 1982.

SOLOMON, M. R.; SCHOPLER J. "Self-consciousness and clothing". Personality and social psychology bulletin, 8(3), p.508-514, 1982.

. The role of products as social stimuli: a symbolic interactionism perspective. Journal of Consumer research. v. 10, Dezembro 1983.

THOMPSON, C. J.; HAYTKO, D. L Speaking of fashion consumers' uses of fashion discourses and the appropriation of countervailing cultural meaning. Journal of consumer research, Junho 1997.

\section{NOTAS}

${ }^{[1]}$ Ao ser perguntado, em uma entrevista, em que parte do corpo a mulher deveria passar perfume, Chane respondeu: Onde ela quiser ser beijada (AMARAL, 2004).

${ }^{[2]}$ Essas subculturas existem dentro de comunidades maiores, mas têm gostos, interesses, preferências, tabus, estilos e atitudes próprios com relação à moda. Por exemplo, na sociedade norte-americana, os negros representam uma subcultura da cultura estadunidense, diferentes na sua essência dos brancos WASP (sigla para abreviar o termo White, Anglo-Saxan and Protestant, ou seja, "branco, descendente de ingleses e protestante"). ${ }^{[3]}$ Saiba mais em: <http://www.datavale-sp.com.br/CCEB.pdf>

${ }^{[4]} 0$ dendograma é um diagrama que demonstra a hierarquia e a relação entre aspectos funcionais e simbólicos. 